Original Research Paper

\title{
Fabrication of Ni, Si and Mg Supersaturated Solid Solutions in Al by Mechanical Alloying
}

\author{
${ }^{1}$ A. Sedano, ${ }^{1}$ A. Molina, ${ }^{1}$ S.A. Serna, ${ }^{3}$ R.A. Rodríguez-Díaz and ${ }^{2}$ A. Torres-Islas \\ ${ }^{1}$ Centro de Investigación en Ingeniería y Ciencias Aplicadas, \\ Universidad Autónoma del Estado de Morelos, Cuernavaca, Morelos, México \\ ${ }^{2}$ Facultad de Ciencias Quimicas e Ingeniería, \\ Universidad Autónoma del Estado de Morelos, Cuernavaca, Morelos, México \\ ${ }^{3}$ Universidad Popular Autónoma del Estado de Puebla, Puebla, Puebla, México
}

\section{Article history}

Received: 04-11-2019

Revised: 22-01-2020

Accepted: 20-02-2020

Corresponding Author:

A. Molina

Centro de Investigación en

Ingeniería y Ciencias Aplicadas,

Universidad Atuonoma del Estado

de Morelos, Mexico

Email: arturo_molina@uaem.mx

\begin{abstract}
In this work, a comparison between the synthesis process of nanostructured $\mathrm{Al}$ base alloys modified with $\mathrm{Si}, \mathrm{Ni}$ and $\mathrm{Mg}$ and the formation of their respective supersaturated solid solution is presented. The samples were obtained via Mechanical Alloying (MA) at a speed of $300 \mathrm{RPM}$ for 2, 5, 10, 20 and $30 \mathrm{~h}$ under an inert Ar atmosphere. Lattice parameter evolution, semiquantitative X-Ray Diffraction Analysis and SEM micrographs were correlated to determine the attained solubility in the Al matrix. The results showed that powder refinement and solubility rates are directly affected by the hardness of the solute element and the limiting solubility in equilibrium state respectively. Therefore the Al-Mg alloy achieved the highest solubility of the samples after $10 \mathrm{~h}$ of milling, meanwhile, the Al-Si alloy showed the lowest solubility even after $20 \mathrm{~h}$ of milling. Microstructural analyses by X-Ray Diffraction revealed that the lattice parameter showed different behavior depending on the alloy system, in some cases showing a deviation from the behavior predicted by Vegard's law. Finally, this work demonstrates that the successful synthesis of supersaturated solid solutions via MA is dependent on the alloy system as well as milling conditions.
\end{abstract}

Keywords: Mechanical Alloying, Milling, Solid Solution, Aluminum Alloys, Powder Metallurgy

\section{Introduction}

New technological developments require advanced materials with properties such as lightweight, high strength, fatigue resistance and corrosion resistance (Atul et al., 1993; Heinz et al., 2000; Yvon and Carré, 2009), but on the other hand, it's desirable that they are low cost to produce with raw material availability. Good candidates include microstructurally designed Al alloys, capable of being tailored to withstand harsh environments while exhibiting good mechanical properties essential for advance engineering applications (Reed et al., 2009; Nie and Muddle, 1998; Vajpai et al., 2015). Some of the techniques employed include Solidsolution strengthening, High-pressure torsion, large strain extrusion and spark plasma sintering, these techniques have shown to be capable of producing materials such as Ni-based super alloys (Takizawa et al., 2015), as well as Al, Mg and steel alloys with ultrafinegrained structures and superior strength (Figueiredo and Langdon, 2012) and Li-ion batteries with grains conserved in the nano-scale range that enhances conductivity (Kali and Mukhopadhyay, 2014). Therefore, the ability to control the microstructure of the materials paves the way to future technological advances capable of revolutionizing aerospace, automotive, medical and production industries (Schinhammer et al., 2010; Brenne et al., 2016; Burger et al., 1996).

Supersaturated Solid Solutions (SSS) consist in alloys with solute contents that exceed the solid solubility limit under equilibrium conditions (Suryanarayana and Froes, 1992), this higher content of solute elements in the crystal lattice have shown to improve the mechanical properties of the base metal 
trough mechanisms such as solid solution strengthening, precipitation strengthening, grain boundary strengthening and high dislocation densities (Suryanarayana, 1996). The main advantage of materials with such strengthening mechanisms is that they can be designed microstructurally for their intended application (Eskin, 2003), this is done via different heat treatment regimens that produces metal matrix composites (MMC) with a refined microstructure and a controlled precipitation of second phases capable of withstanding harsh environments while exhibiting high strength, corrosion resistance and good wear resistance. Therefore, the development of new low weight $\mathrm{Al}$ alloys with improved mechanical properties compasses the investigation of SSS, their heat treatment regimens and the mechanisms involved in their synthesis via different techniques. Different techniques to produces SSS alloys have been widely studied, but the Mechanical Alloying (MA) process has been continuously proved to be a reliable synthesis method with some added benefits. Contrary to other methods such as the Rapid Solidification Process (RSP), the MA process is capable of providing greater solubility extension and highly refined homogenous powders (Patra et al., 2016); this is obtained through the constant collisions exerted on the milled powder that creates nonequilibrium conditions (Shingu and Ishihara, 1996). Overall, the MA process consists of a more flexible method to produce SSS but one that requires the optimization of the milling parameters to produce the required system conditions to obtain SSS alloys.

Previous works have shown that annealing treatment of powders after milling or high temperatures during milling inhibit the formation of SSS as it produces the precipitation of second more stable phases (Schwarz, 1995). Other studies indicate that varying other milling parameters such as the use of Process Control Agents (PCA) and controlled atmospheres impact greatly the synthesis of SSS (Li et al., 2010). There is also contradicting evidence concerning the use of HumeRothery rules to predict the formation of SSS for the MA process (Moumeni et al., 2006; Bansal et al., 1994). Comparative studies of RSP (Suryanarayana, 2018; Mukhopadhyay et al., 2008) with MA still have not concluded the difference in mechanisms that produce contradictory behaviors for the same alloying systems. Thus, there is still a knowledge gap concerning the driving forces behind the formation of SSS via MA and a reliable method that helps us to predict the successful synthesis of SSS.

This work aims to compare the mechanisms behind the synthesis of SSS for different alloying systems (Al-Si, Al$\mathrm{Ni}$ and $\mathrm{Al}-\mathrm{Mg}$ ) under the same milling parameters. The rate of solubility, particle refinement, lattice strain evolution and microstructural properties are examined and compared. This is intended for determining the alloy system characteristics that affect the synthesis process via MA and differentiate the behavior demonstrated to that as expected by other techniques. In future works, this may help in the selection of milling parameter (such as milling time and speed regime) to successfully achieve the synthesis of SSS.

\section{Materials and Methods}

Aluminum, nickel, silicon and magnesium powders with purity above $99.5 \%$ and an average particle size of 50 microns were milled in tool-grade steel vials with stainless steel balls and with a Ball to Powder Ratio (BPR) of 10:1. The milled powder mixtures consisted of Al-3Ni (wt.\%), Al-3Si (wt.\%) and Al-3Mg (wt.\%) with 0.3 wt. \% of stearic acid added as Process Control Agent (PCA) (Fogagnolo et al., 2006). A low-energy planetary ball mill (FRITSCH, Pulverisette model) was used for milling the powders at $300 \mathrm{rpm}$ for 2, 5, 10, 50 and $30 \mathrm{~h}$ under an argon atmosphere to protect the obtained powders from reacting.
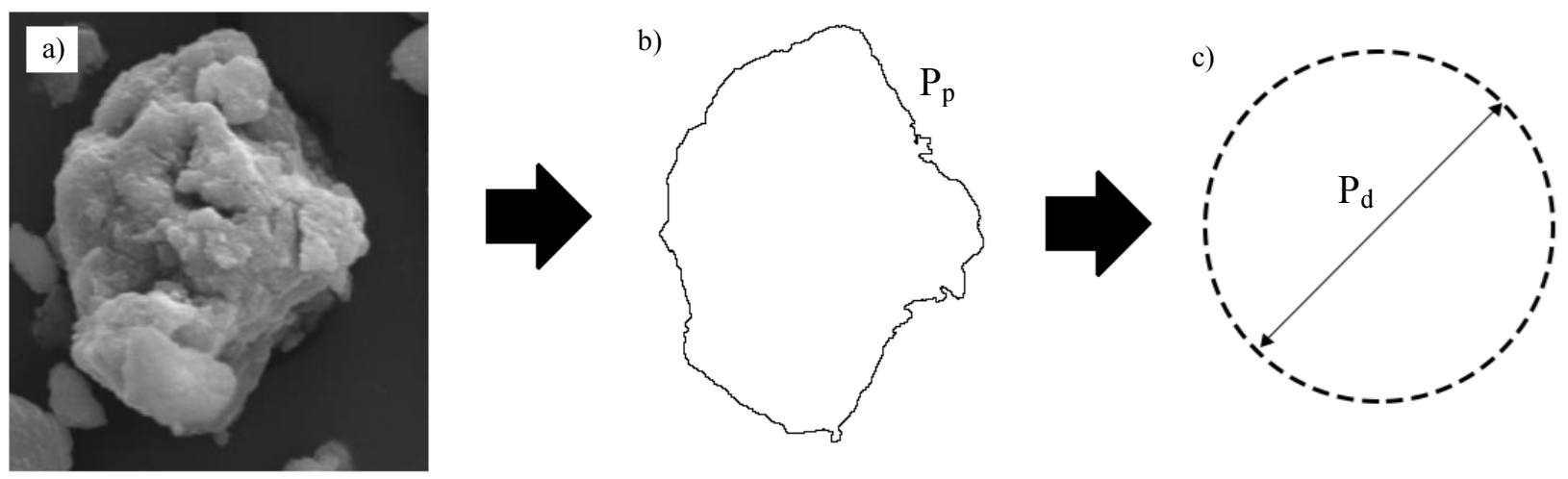

Fig. 1: Image processing illustration of an observed particle (a), its calculated perimeter $\mathrm{Pp}$ (b) and equivalent circular perimeter diameter Pd (c) 
The resulting powder samples were characterized by Scanning Electron Microscopy (SEM) with a LEO 1450 equipment to determine the microstructural evolution and powder properties during the milling process with the aid of an image processing program (ImageJ) for measuring the perimeter of the observed particles (Fig. 1) to calculate the equivalent circular perimeter diameter according to Equation 1:

$P_{d}=\frac{P_{p}}{\pi}$

Where:

$P_{d}=$ The equivalent circular perimeter diameter $[\mu \mathrm{m}]$

$P_{p}=$ The particle perimeter $[\mu \mathrm{m}]$

X-Ray Diffraction (XRD) patterns were obtained with a BRUKER D2 PHASER diffractometer using CuK $\alpha$ radiation over a 2-theta range of 20 to 80 degrees. Calculation of lattice parameter from Bragg's Law as described in Equation 2 where performed for solubility analysis according to Vegard's Law (Equation 3) and compared to those obtained by semiquantitative analysis.

\section{Bragg's Law:}

$n \lambda=2 d \sin \theta$

Where:

$n=$ And integer

$\lambda=$ The wavelength of the characteristic x-rays

$d=$ The interplanar spacing [nm]

$\theta=$ The Bragg angle [radians]

Vegard's Law:

$a_{S S}=\left(1-x_{A}\right) a_{A}+x_{B} a_{B}$

Where:

$a_{S S} \quad=$ The lattice parameter of the solid solution $[\AA]$

$a_{A}$ and $a_{B}=$ The lattice parameter of the alloying elements $A$ and $B$ respectively [ $\AA]$

$x_{A}$ and $x_{B}=$ The molar fraction of the alloying elements $A$ and $B$ respectively [at. \%]

Crystallite size and micro strain during the mechanical alloying process was obtained from Williamson-Hall plots according to Equation 4:

$\beta \cos \theta=\frac{K \lambda}{d}+2 \varepsilon \sin \theta$

Where:

$\beta=$ The peak breadth at half maximum $\theta=$ The Bragg angle [radians]

$K=$ The Scherrer constant $[\approx 0.9]$

$\lambda=$ The wavelength of the characteristic x-rays [nm]

$d=$ The average crystallite size [nm]

$\varepsilon=$ The average lattice strain [\%]

\section{Results}

\section{Scanning Electron Microscopy Imaging}

Initial powders SEM micrographs (Fig. 2) show different morphological characteristics for the powders, consisting in spherical for those of $\mathrm{Al}$ (Fig. 2a), amorphous for those of $\mathrm{Mg}$ (Fig. 2d) and irregular for those of Ni (Fig. 2b) and Si (Fig. 2c) powders. Their difference in morphology is due to the use of distinct production methods, Al powders where atomized meanwhile, machining was used for those of $\mathrm{Ni}$ and $\mathrm{Si}$ and mechanical milling processing was used for the $\mathrm{Mg}$ samples. Morphological properties such as particle shape, particle size, particle size distribution, agglomerates, etc. have been shown to affect principally the initial stages of milling (Parvin et al., 2008) since, after continuous impacts, the powders converge into a predominantly amorphous morphology (Fogagnolo et al., 2003).

After $30 \mathrm{~h}$ of milling, the morphology of the powders became predominantly amorphous for the Al-Si (Fig. 3a) and Al-Ni system (Fig. 3b) and predominantly quasispherical for the Al-Mg system (Fig. 3c). The hardness of initial powders affect the evolution of the system, therefore a ductile-brittle system has been shown to result in higher cold work and fracture than that of a ductile-ductile system (Gheisari et al., 2009). Hence in the Al-Si and Al-Ni samples, more amorphous final powders are observed; meanwhile, the Al-3\% Mg sample shows that the magnesium high cold-work hardening rate and ductility gave resulted in an enhanced particle refinement while maintaining a very similar morphology to that of the Al initial powders. This higher refinement in the ductile-ductile system is congruent with previous studies that have compared the morphological evolution of different alloying systems by MA (Zhou and Rao, 2004).

Figure 4 shows that the more efficient system for homogeneous particle refinement was that of the Al-3\% $\mathrm{Mg}$, since it displays a narrower particle size distribution represented by the upper and lower quartiles. In contrast to this, the less homogeneous powders was the $\mathrm{Al}-3 \% \mathrm{Ni}$ sample, which displays higher upper and lower quartiles difference as well as higher maximum and minimum values. Nonetheless, the $\mathrm{Al}-\mathrm{Mg}$ system obtained the highest average particle size; this is behavior is attributed to the ductility of $\mathrm{Mg}$ and $\mathrm{Al}$, which provides a $\mathrm{MA}$ process dominated by cold-welding. It is worth mentioning, that the Al-Ni system displayed low homogenization in particle size, probably related to the irregular size of the initial Ni powders. 


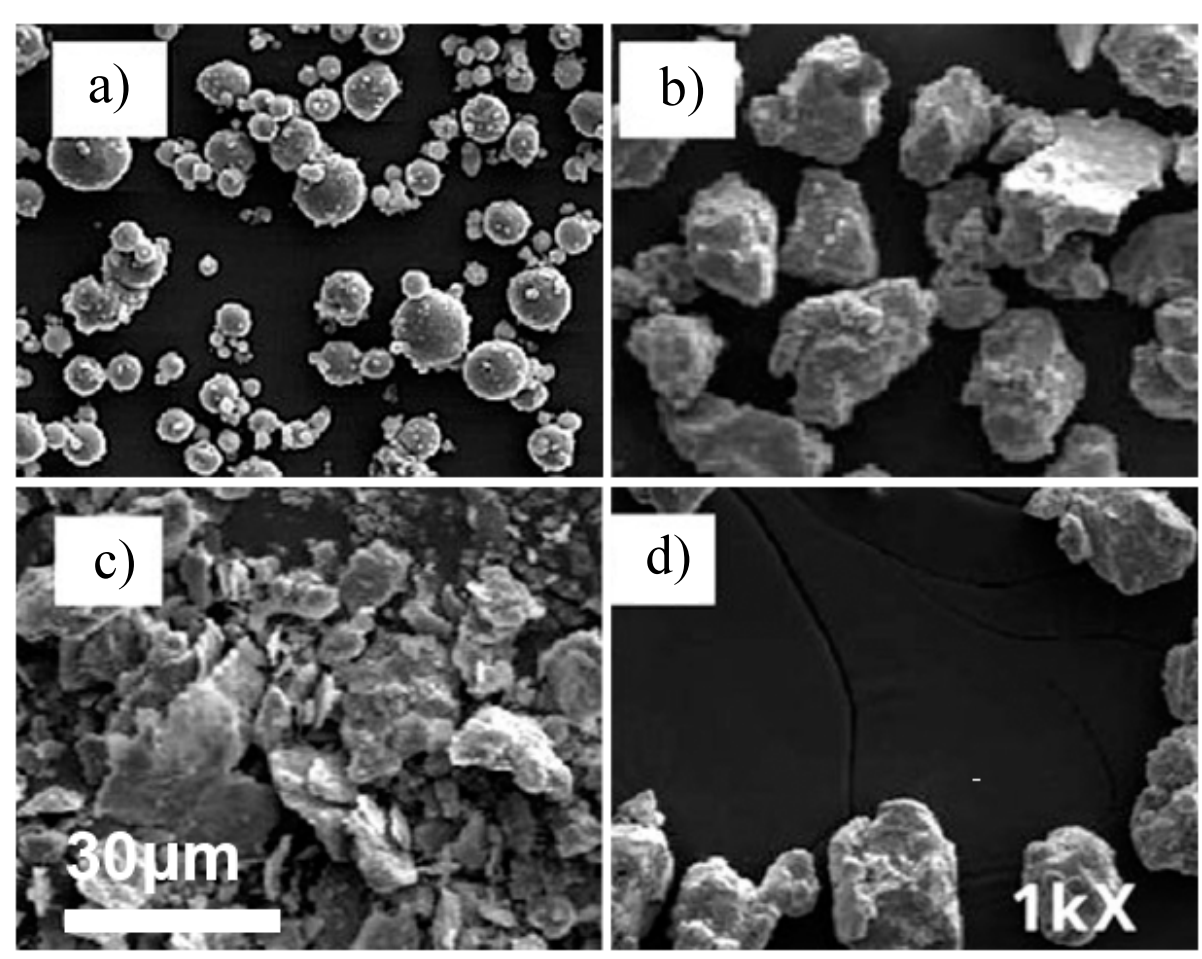

Fig. 2: SEM micrographs of the initial $\mathrm{Al}(\mathrm{a}), \mathrm{Ni}(\mathrm{b}), \mathrm{Si}(\mathrm{c})$ and $\mathrm{Mg}(\mathrm{d})$ powders
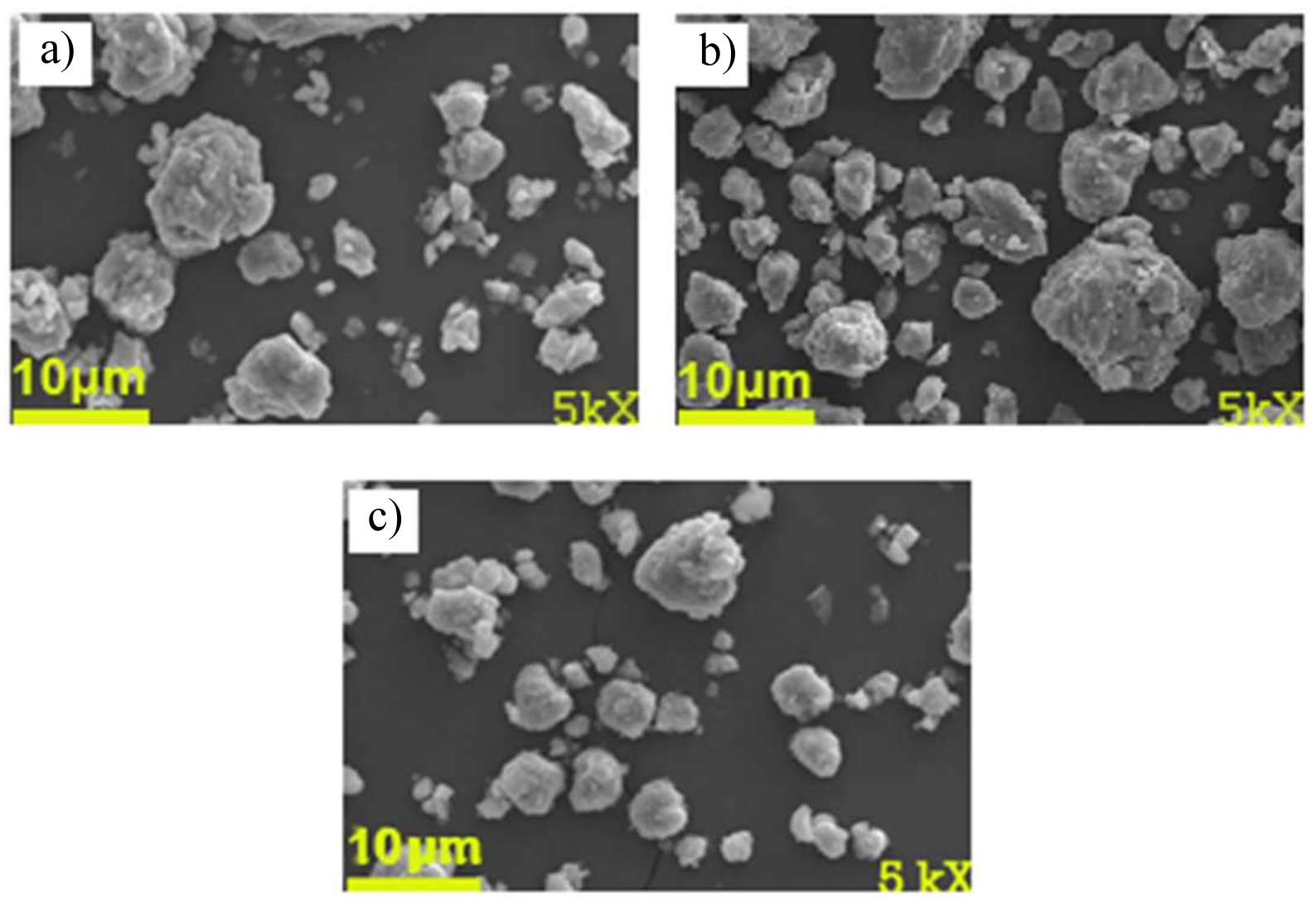

Fig. 3: SEM micrographs of the $\mathrm{Al}-3 \% \mathrm{Si}(\mathrm{a}), \mathrm{Al}-3 \% \mathrm{Ni}(\mathrm{b})$ and $\mathrm{Al}-3 \% \mathrm{Mg}$ (c) powders after $30 \mathrm{~h}$ of milling time 


\section{Phase Identification}

XRD patterns revealed that during the MA process, the peaks corresponding to the solute elements disappeared at different times depending on the alloying system, the AlMg XRD pattern (Fig. 5a) shows that after $10 \mathrm{~h}$ of milling time, the Mg peaks are barely noticeable, semiquantitative analysis showd that the observable area under the curve after $30 \mathrm{~h}$ of milling corresponds to $0.23 \mathrm{wt} . \%$ of $\mathrm{Ni}$. A small content of $\mathrm{Al}_{2} \mathrm{O}_{3}$ as a secondary phase is observable after $20 \mathrm{~h}$. As it does not contain $\mathrm{Mg}$, it should not affect notoriously the $\mathrm{Mg}$ content dissolved in the Al Matrix, therefore by semiquantitative analysis, the Al-Mg system achieved supersaturation (above $1.2 \mathrm{wt} \%$ of $\mathrm{Mg}$ solubilized) after $10 \mathrm{~h}$ of milling. The next system that presented the most noticeable reduction in solute element peaks was the Al-Ni system (Fig. 5b), in this case, the superposition of $\mathrm{Al}$ and $\mathrm{Ni}$ peaks (near 44.5 2-theta degrees) required the deconvolution of the XRD patterns, the semiquantitative analyses showed that as $\mathrm{Ni}$ has $0 \%$ solubility at room temperature, the supersaturation was successful even after the initial stages of milling furthermore, it was possible to obtain approximately $2.78 \%$ of solubility. Finally, the Al-Si patterns (Fig. 5c) showed during all the milling stages the presence of $\mathrm{Si}$ peaks, agreeing with this result, the semiquantitative analysis showed that it achieved the less amount of solubility in the $\mathrm{Al}$ matrix.

\section{Crystallite Refinement}

To fully study the phenomenon occurring during the MA process, it is necessary to compare crystallite size evolution and lattice strain. Grain size refinement increased with milling time in all the alloying systems studied in this work and can be observed in the broadening of the Al peaks in XRD patterns. A subtle variation of the phenomenon between the samples is shown in the Williamson-Hall plots (Fig. 6). This can be attributed to the low concentration of the alloying elements. Most noticeable, all the samples achieved almost maximal crystallite size refinement after $20 \mathrm{~h}$ of milling time, displaying a balance of the cold welding and fracture events after the early stages of milling $(10 \mathrm{~h})$. This resulted in the typical asymptotic behavior of the mechanical alloying process (Cocco et al., 2000) that can be seen most noticeable in the Al-3Si (wt.\%) system in Fig. $6 \mathrm{c}$ probably due to the higher hardness value of $\mathrm{Si}$ and high melting point that hinders further dislocation creation and movement (Garroni et al., 2014).

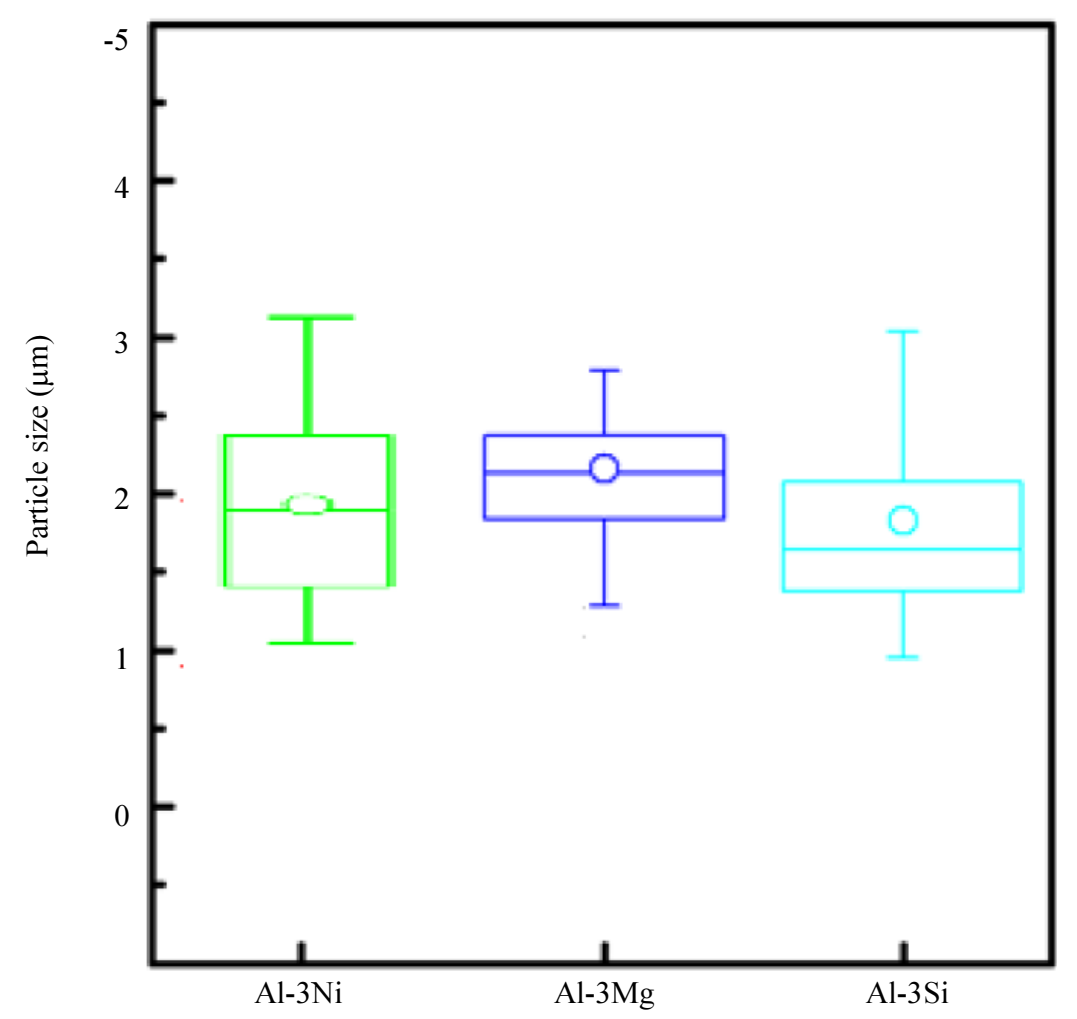

Fig. 4: Box plot of particle size distribution (equivalent circular perimeter diameter $\mathrm{Pd}$ ) after $30 \mathrm{~h}$ of milling time for the $\mathrm{Al}-3 \% \mathrm{Ni}$, $\mathrm{Al}-3 \% \mathrm{Mg}$ and $\mathrm{Al}-3 \% \mathrm{Si}$ powders. Average value is depicted with a circle (O), 25th to 75 th percentiles appear as a box, minimum and maximum values as whiskers 


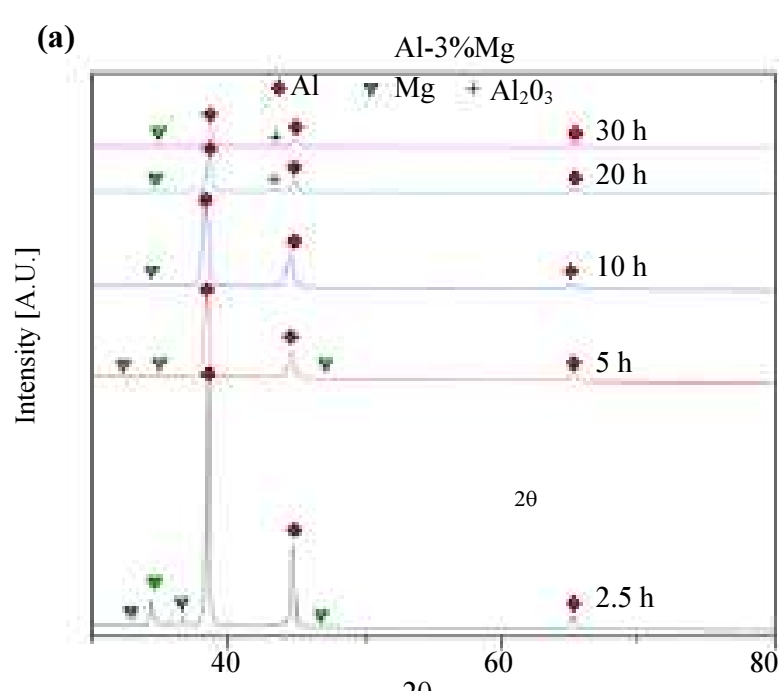

$2 \theta$ (b)

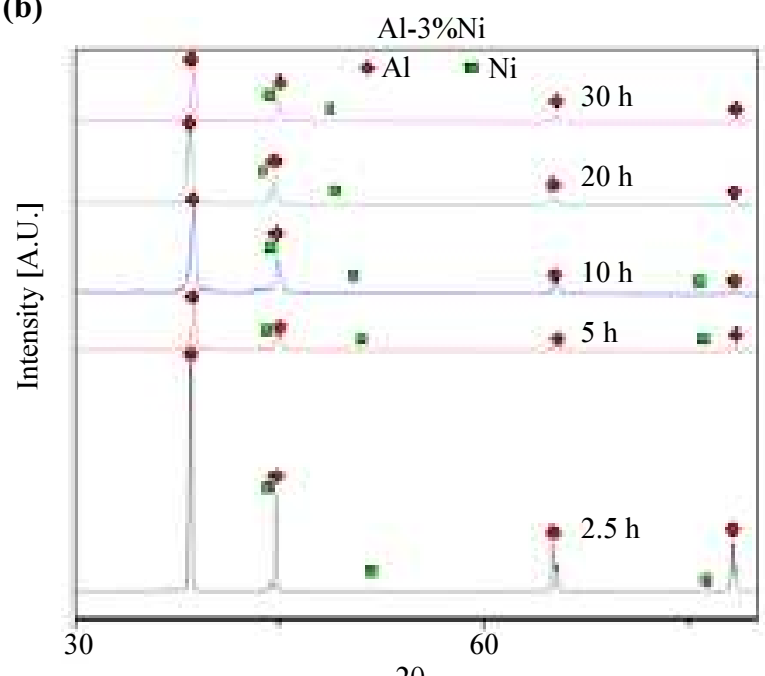

(c)

$\mathrm{Al}-3 \% \mathrm{Si}$

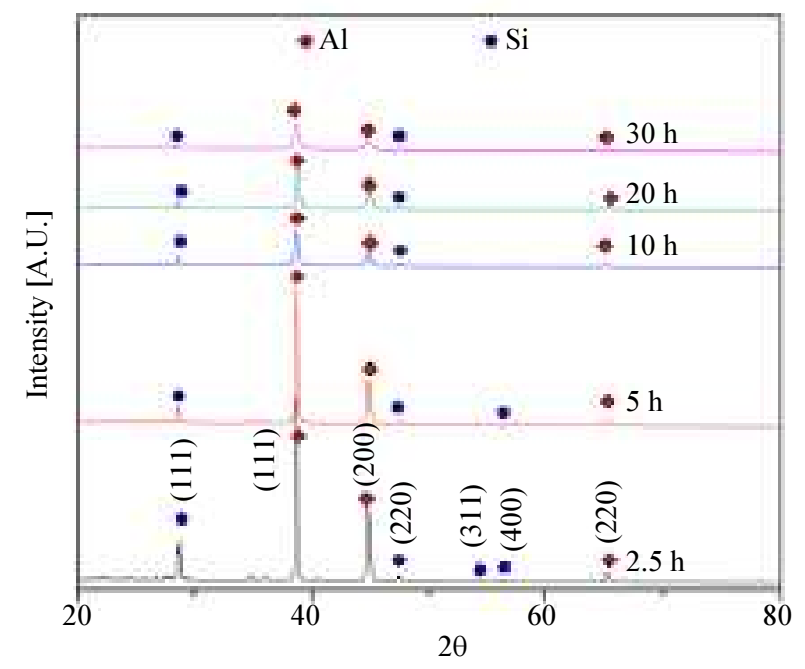

Fig. 5: XRD patterns of the (a) Al-3Mg(wt.\%), (b) Al-3Ni(wt.\%) and Al-3Si(wt.\%) alloying systems during the MA process.

The minimum grain sizes obtained were $70 \mathrm{~nm}$ for the Al-3Ni (wt.\%) system, $55 \mathrm{~nm}$ for the $\mathrm{Al}-3 \mathrm{Mg}$ (wt.\%) system and $47 \mathrm{~nm}$ for the A-3Si (wt.\%) system, these values are in agreement with those corresponding to the plot published by (Koch, 1993) (Fig. 7) in which the minimum grain size of various alloys obtained by the MA technique were shown to display an inverse relationship with their melting point, the minimum grain size of the obtained values in this work are shown with a positive deviation in the graph due to low milling energy conditions, this statement holds true also when taking into account the best precision of the XRD technique in crystallite size determination $( \pm 10 \%)$ as discussed by (Al-Aqeeli et al., 2008).

Lattice strain calculated by Williamson-Hall plots showed to increases as milling time elapsed (Fig. 6), with some noticeable relaxation phenomenon in the $\mathrm{Al}-3 \mathrm{Mg}$ (wt.\%) system after $10 \mathrm{~h}$ of milling time, this behavior has been shown to be related to accumulation of defects, crystal lattice reordering and heating during the MA process as shown by Cryogenic Milling with higher lattice strain values and lower occurrence of lattice relaxation (Zhou et al., 2003). It is observable a maximum increase in lattice strain at initial milling stages for all the alloying systems studied in this work, this behavior is due to the increase in work hardening experienced during the MA process that translates into higher energy required to deformation to take place (Azimi and Akbari, 2011) and therefore it can be observed slower rates of lattice strain as milling time elapses. 

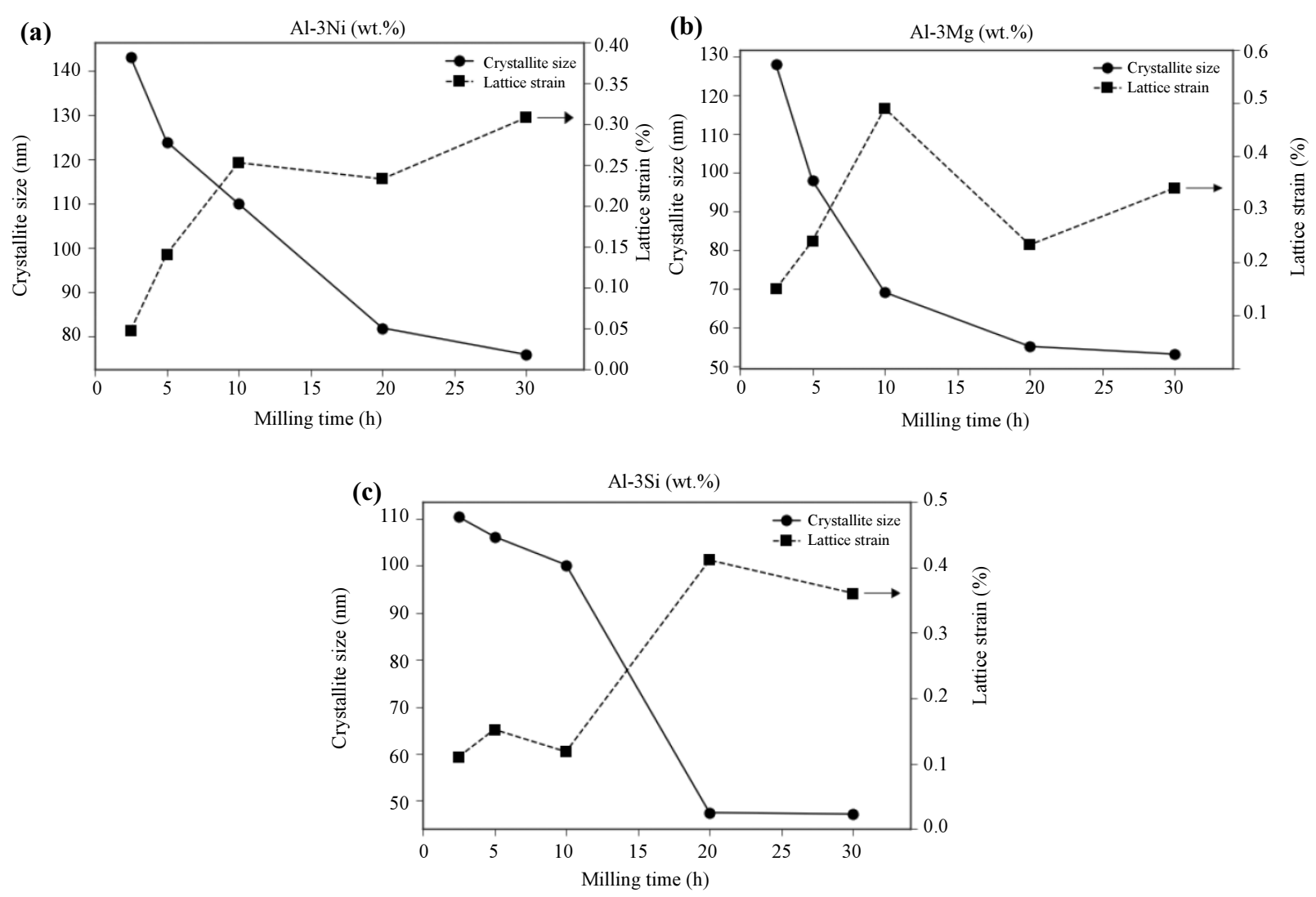

Fig. 6: Williamson-hall plots of the (a) Al-Ni (wt.\%), (b) Al-3Mg (wt.\%) and Al-3Si (wt.\%) alloying systems during the MA process

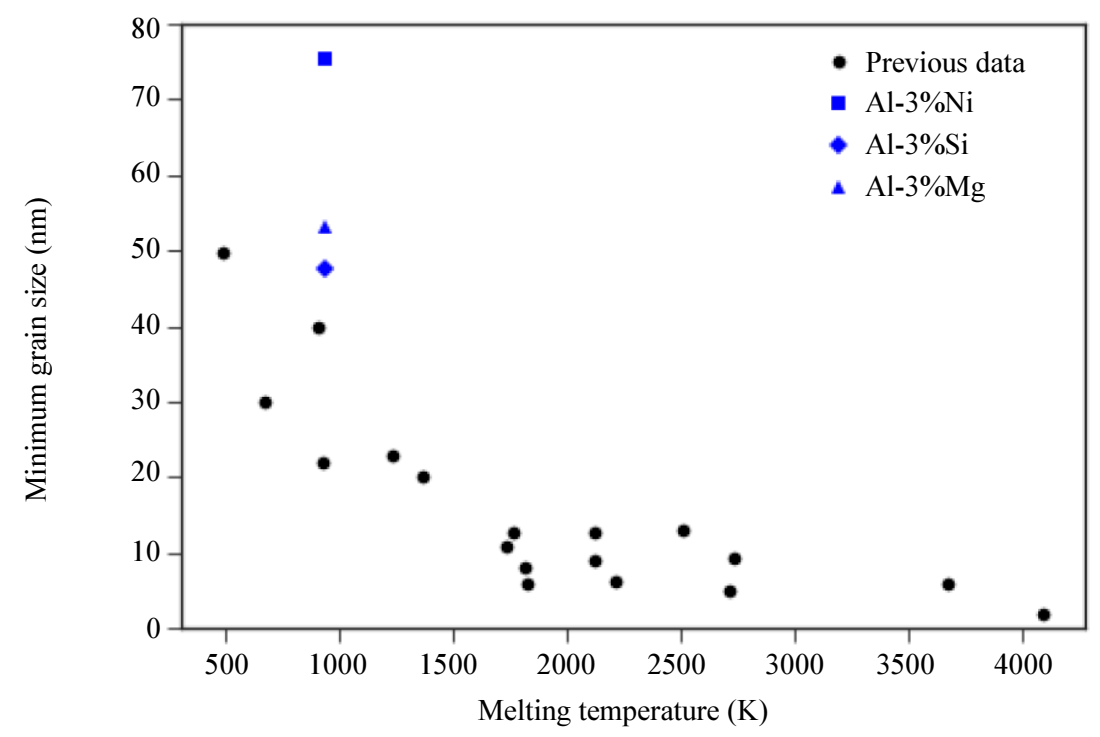

Fig. 7: Minimum grain size obtained via mechanical alloying against melting temperature (Koch, 1993)

\section{Lattice Parameter Evolution}

Lattice parameter calculated during milling time is observed in Fig. 8 and can be inferred from the displacement of XRD patterns peaks. Both the Al-3Ni system and Al-3Si system show oscillations in the lattice parameter that has been previously attributed to contamination (Blázquez et al., 2009), reordering and 
formation of second phases (Kim et al., 1996). Meanwhile, stabilization of the lattice parameter expected in Solid Solutions seems to be only obtained in the Al-Ni system, showing only a small fluctuation in the late stages of milling $(30 \mathrm{~h})$.

The usual method to study the solubility in SSS is through the use of the Vegard's law and lattice parameter calculations. Figure 9 shows the relationship given by Vegard's law between lattice parameter and solubility of the alloying element.

The calculated lattice parameter for the $\mathrm{Al}-\mathrm{Mg}$ system showed a negative deviation from that expected by Vegards law, therefore the final lattice parameter value corresponds to that of a solubility of $3.2 \mathrm{wt} \%$ of $\mathrm{Mg}$, meanwhile the $\mathrm{Al}-\mathrm{Ni}$ and Al-Si systems behaved with no deviations and the obtained solubility values were $2 \%$ and $1.5 \%$ respectively. Furthermore, the Al-Mg system does no presents an asymptotic behavior, rather a linear behavior. Meanwhile, the other samples present an asymptotic behavior characteristic of the MA process. This can be attributed to the enhanced mechanical alloying process in ductile-ductile systems once the fracture-welding process reaches equilibrium (Aizawa and Song, 2016).

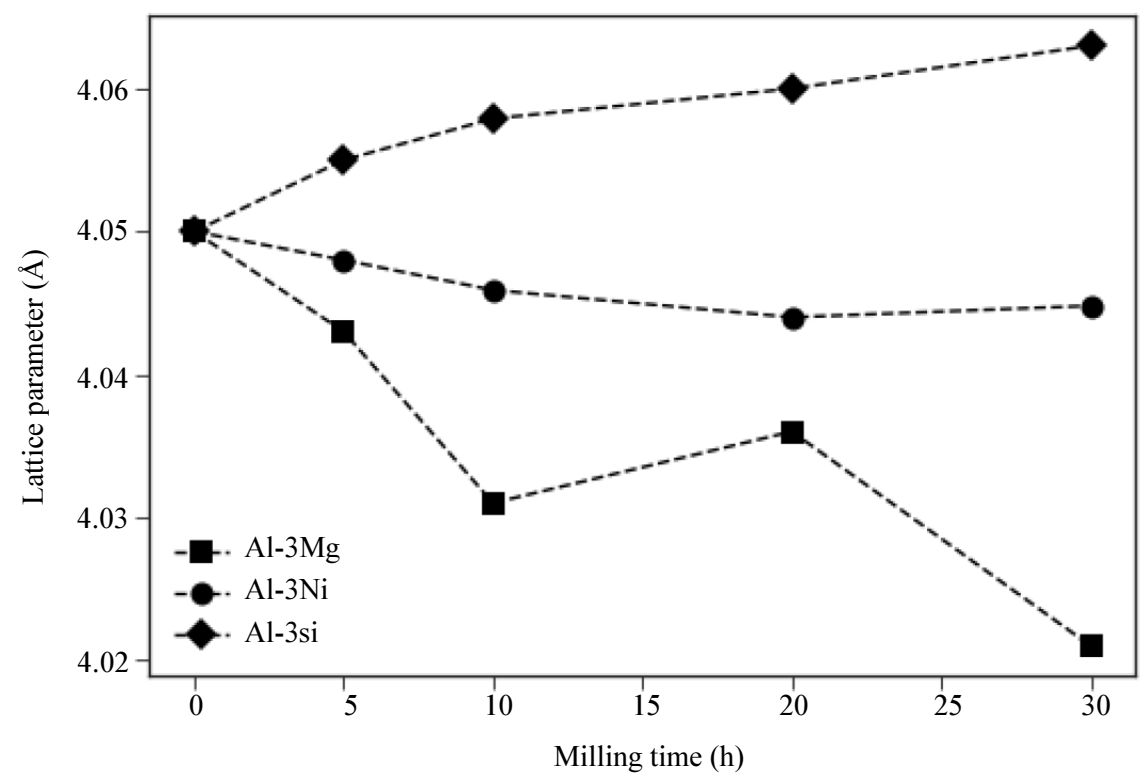

Fig. 8: Calculated Lattice parameter during mechanical alloying

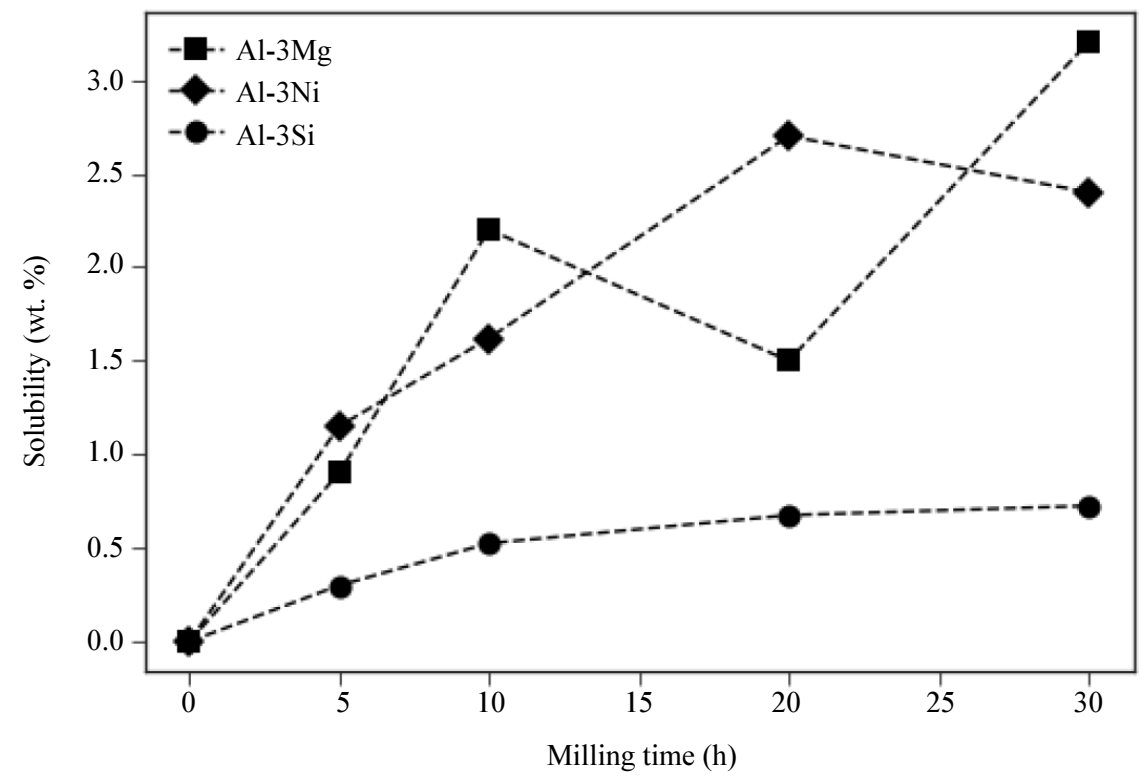

Fig. 9: Solubility of the alloying elements given by Vegard's law during milling time 


\section{General Discussion}

XRD patterns and SEM micrographs show the effects of the collisions imparted by the balls onto the powders during the mechanical alloying process. This translates into cold welding of the particles during the initial stages of the process, with modest particle size and morphology changes. Posterior to this, the energy provided by the collisions fractures the powder and a balance between cold working and fracture is reached in the late stages (Murty and Ranganathan, 1998). The powder processing, therefore, results in particle size and grain size refinement, observable trough the peak broadening of the XRD patterns and corroborated by the Williamson Hall plots calculations, as well as homogenization of the characteristics of the powders during the late stages of milling (Rojas et al., 2006).

The solubility of the alloying elements was approximated by XRD semiquantitative analyses and showed to be congruent with those obtained by Vegard's Law calculations from the obtained lattice parameters. The negative deviation from Vegard's Law in the Al-Mg system and the presence of a small $\mathrm{Al}_{2} \mathrm{O}_{3}$ peak in the XRD pattern seems to indicate Oxygen contamination during the MA process even under an inert $\mathrm{Ar}$ atmosphere. This behavior is similar to those reported by (Botcharova et al., 2003) in which precautions were incapable of preventing contamination from the milling media and environment. Another common phenomenon associated with the contamination of powders can be seen in the oscillation of the lattice parameter and lattice strain during the late stages of milling.

\section{Conclusion}

In this work is demonstrated the viability of producing $\mathrm{SSS}$ of $\mathrm{Al}-3 \mathrm{wt} \% \mathrm{Si}, \mathrm{Al}-3 \mathrm{wt} \% \mathrm{Mg}$ and $\mathrm{Al}-$ $3 \mathrm{wt} \% \mathrm{Ni}$ by mechanical alloying under low energy milling conditions.

Although difficult to obtain, semiquantitative analysis of XRD patterns can be used for guidance of the solubility phenomenon in the MA process, but further precision requires the use of lattice parameter calculations and Vegard's Law.

Vegard's Law is prone to small errors due to contamination from the milling environment, but it nonetheless, it's still plays an important and relevant role in the study of solid solutions obtained by the MA technique.

The solubility rate obtained during the processing of the powders is completely dependent on the alloy system even with low alloying element content.

The mechanisms behind the synthesis of SSS via the MA process are unique to this method and therefore it is incorrect to use results obtained from other processes to infer the expected behavior trough the MA process.

Finally, the results obtained showed that even low concentrations of different alloying elements are capable of affecting the evolution of particle and grain refinement.

\section{Acknowledgement}

This work was financed by CONACyT [Grant Number 402858]; the authors would like to thank sincerely Rene' Guardian Tapia for the support provided in SEM images.

\section{Author's Contributions}

A. Sedano: Designed the research plan, all experimental development of the research, analysis of results and writing of the paper.

A. Molina: Designed the research plan, process of mechanical alloying and mechanical milling, analysis of results and writing of the paper.

S.A. Serna: Participated in the microstructural characterization of the alloys and analysis of results and writing of the paper.

R.A. Rodríguez-Díaz: Performed the X-ray diffraction analysis and analysis of results.

A. Torres-Islas: Participated in the microstructural characterization of the alloys and analysis of results.

\section{Ethics}

This article is original and contains unpublished material. The corresponding author confirms that all of the other authors have read and approved the manuscript and no ethical issues involved.

\section{References}

Aizawa, T. and R. Song, 2006. Mechanically induced reaction for solid-state synthesis of $\mathrm{Mg} 2 \mathrm{Si}$ and Mg2Sn. Intermetallics, 14: 382-391.

DOI: 10.1016/j.intermet.2005.07.003

Al-Aqeeli, N., G. Mendoza-Suarez, C. Suryanarayana and R.A.L. Drew, 2008. Development of new Albased nanocomposites by mechanical alloying. Mater. Sci. Eng. A, 480: 392-396.

DOI: $10.1016 /$ j.msea.2007.09.060

Atul, H., K. Amiya and G.L. Terence, 1993. Superplasticity in advanced materials. Mater. Sci. Eng. R: Reports, 10: 237-274. DOI: 10.1016/0927-796X(93)90009-R

Azimi, M. and G.H. Akbari, 2011. Development of nanostructure $\mathrm{Cu}-\mathrm{Zr}$ alloys by the mechanical alloying process. J. Alloys Compounds, 509: 27-32. DOI: $10.1016 /$ j.jallcom.2010.08.071

Bansal, C., Z. Gao, L. Hong and B. Fultz, 1994. Phases and phase stabilities of $\mathrm{Fe}_{3} \mathrm{X}$ alloys $(\mathrm{X}=\mathrm{Al}$, As, $\mathrm{Ge}, \mathrm{In}, \mathrm{Sb}, \mathrm{Si}, \mathrm{Sn}, \mathrm{Zn})$ prepared by mechanical alloying. J. Applied Phys., 76: 5961-5966. DOI: $10.1063 / 1.358375$ 
Blázquez, J.S., J.J. Ipus, M. Millán, V. Franco and A. Conde et al., 2009. Supersaturated solid solution obtained by mechanical alloying of $75 \% \mathrm{Fe}, 20 \%$ $\mathrm{Ge}$ and $5 \% \mathrm{Nb}$ mixture at different milling intensities. J. Alloys Compounds, 469: 169-78.

DOI: 10.1016/j.jallcom.2008.01.144

Botcharova, E., M. Heilmaier, J. Freudenberger, G. Drew and D. Kudashow et al., 2003. Supersaturated solid solution of niobium in copper by mechanical alloying. J. Alloys Compounds, 351: 119-25. DOI: 10.1016/S0925-8388(02)01025-3

Brenne, F., A. Taube, M. Pröbstle, S. Neumeier and D. Schwarze et al., 2016. Microstructural design of Nibase alloys for high-temperature applications: Impact of heat treatment on microstructure and mechanical properties after selective laser melting. Progress Additive Manufacturing, 1: 141-151. DOI: $10.1007 / \mathrm{s} 40964-016-0013-8$

Burger, G., A. Gupta, P. Jeffrey and D. Lloyd, 1995. Microstructural control of aluminum sheet used in automotive applications. Mater. Characterizat., 35: 23-39. DOI: 10.1016/1044-5803(95)00065-8

Cocco, G., F. Delogu and L. Schiffini, 2000. Toward a quantitative understanding of the mechanical alloying process. J. Mater. Synthesis Proc., 8: 167-180. DOI: $10.1023 / \mathrm{A}: 1011308025376$

Eskin, D., 2003. Decomposition of supersaturated solid solutions in Al-Cu-Mg-Si alloys. J. Mater. Sci., 38: 279-290. DOI: 10.1023/A:1021109514892

Figueiredo, R. and T. Langdon, 2012. Fabricating ultrafine-grained materials through the application of severe plastic deformation: A review of developments in Brazil. J. Mater. Res. Technol., 1: 55-62. DOI: 10.1016/S2238-7854(12)70010-8

Fogagnolo, J., F. Velasco, M. Robert and J. Torralba, 2003. Effect of mechanical alloying on the morphology, microstructure and properties of aluminium matrix composite powders. Mater. Sci. Eng. A, 342: 131-43.

DOI: $10.1016 / \mathrm{S} 0921-5093(02) 00246-0$

Garroni, S., S. Soru, S. Enzo and F. Delogu, 2014. Reduction of grain size in metals and metal mixtures processed by ball milling. Scripta Mater., 88: 9-12. DOI: $10.1016 /$ j.scriptamat.2014.06.012

Gheisari, K., S. Javadpour, J.T. Oh and M. Ghaffari, 2009. The effect of milling speed on the structural properties of mechanically alloyed $\mathrm{Fe}-45 \% \mathrm{Ni}$ powders. J. Alloys Compounds, 472: 416-20. DOI: $10.1016 /$ j.jallcom.2008.04.074

Heinz, A., A. Haszler, C. Keidel, S. Moldenhauer and R. Benedictus et al., 2000. Recent development in aluminium alloys for aerospace applications. Mater. Sci. Eng. A, 280: 102-107. DOI: $10.1016 / \mathrm{S} 0921-5093(99) 00674-7$
Kali, R. and A. Mukhopadhyay, 2014. Spark plasma sintered/synthesized dense and nanostructured materials for solid-state Li-ion batteries: Overview and perspective. J. Power Sources, 247: 920-931. DOI: 10.1016/j.jpowsour.2013.09.010

Kim, H.S., D.S. Suhr, G.H. Kim and D.W. Kum, 1996. Analysis of X-ray diffraction patterns from mechanically alloyed Al-Ti powders. Metals Mater., 2: 15-21. DOI: $10.1007 / \mathrm{BF} 03025942$

Koch, C., 1993. The synthesis and structure of nanocrystal line materials produced by mechanical attrition: A review. Nanostructured Mater., 2: 109-129. DOI: 10.1016/0965-9773(93)90016-5

Li, L., T. Qiu, J. Yang and Y. Feng, 2010. Synthesis of Nanocrystal line $\mathrm{Ag}-\mathrm{Cu}$ supersaturated solid solution by mechanical alloying. Adv. Mater. Res., 92: 271-276.

DOI: 10.4028/www.scientific.net/AMR.92.271

Moumeni, H., S. Alleg and J. Greneche, 2006. Formation of ball-milled Fe-Mo nanostructured powders. J. Alloys Compounds, 419: 140-144. DOI: 10.1016/j.jallcom.2006.03.040

Mukhopadhyay, N.K., D. Mukherjee, S. Dutta, R. Manna and D.H. Kim et al., 2008. Synthesis and characterization of nanocrystal line and amorphous (A14Cu9)94.5Cr5.5 $\gamma$-brass alloy by rapid solidification and mechanical milling. J. Alloys Compounds, 457: 177-184. DOI: $10.1016 /$ j.jallcom.2007.03.043

Murty, B. and S. Ranganathan, 1998. Novel materials synthesis by mechanical alloying/milling. Int. Mater. Rev., 43: 101-141. DOI: 10.1179/imr.1998.43.3.101

Nie, J. and B. Muddle, 1998. Microstructural design of high-strength aluminum alloys. J. Phase Equilibria, 19: 543-551. DOI: 10.1361/105497198770341734

Parvin, N., R. Assadifard, P. Safarzadeh, S. Sheibani and P. Marashi, 2008. Preparation and mechanical properties of SiC-reinforced Al6061 composite by mechanical alloying. Mater. Sci. Eng. A, 492: 134-140. DOI: 10.1016/j.msea.2008.05.004

Patra, A., S. Karak and S. Pal, 2016. Effects of mechanical alloying on solid solubility. Adv. Eng. Forum, 15: 17-24.

DOI: $10.4028 /$ www.scientific.net/AEF.15.17

Reed, R., T. Tao and N. Warnken, 2009. Alloys-ByDesign: Application to nickel-based single crystal superalloys. Acta Mater., 57: 5898-5913. DOI: 10.1016/j.actamat.2009.08.018

Rojas, P.A., A. Peñaloza, C.H. Wörner, R. Fernández and A. Zúñiga, 2006. Supersaturated $\mathrm{Cu}-\mathrm{Li}$ solid solutions produced by mechanical alloying. J. Alloys Compounds, 425: 334-338.

DOI: $10.1016 /$ j.jallcom.2006.01.032 
Schinhammer, M., A. Hänzi, J. Löffler and P. Uggowitzer, 2010. Design strategy for biodegradable Fe-based alloys for medical applications. Acta Biomater., 6: 1705-1713. DOI: 10.1016/j.actbio.2009.07.039

Schwarz, R.B., 1998. Microscopic model for mechanical alloying. Mater. Sci. Forum, 269: 665-674.

DOI: 10.4028/www.scientific.net/MSF.269-272.665

Shingu, P. and K. Ishihara, 1996. Non-equilibrium materials by mechanical alloying (Overview). Mater. Tran. JIM, 36: 96-101.

DOI: 10.2320/matertrans 1989.36.96

Suryanarayana, C. and F. Froes, 1992. Light metals synthesis by mechanical alloying. Mater. Sci. Forum, 88: 445-452.

DOI: 10.4028/www.scientific.net/MSF.88-90.445

Suryanarayana, C., 1996. Recent advances in the synthesis of alloy phases by mechanical alloying/milling. Metals Mater., 2: 195-209. DOI: $10.1007 / \mathrm{BF} 03026094$

Suryanarayana, C., 2018. Phase formation under nonequilibrium processing conditions: Rapid solidification processing and mechanical alloying. J. Mater. Sci., 53: 13364-13379. DOI: 10.1007/s10853-018-2197-4
Takizawa, Y., K. Otsuka, T. Masuda, T. Kajita and M. Yumoto et al., 2015. High-strain rate superplasticity of Inconel 718 through grain refinement by highpressure torsion. Mater. Sci. Eng. A, 648: 178-182. DOI: 10.1016/j.msea.2015.09.023

Vajpai, K., M. Ota, T. Watanabe and R. Maeda, 2014. The development of high performance Ti-6Al-4V Alloy via a unique microstructural design with bimodal grain size distribution. Metallurgical Mater. Tran. A, 46: 903-914. DOI: $10.1016 /$ j.actamat.2009.08.018

Yvon, P. and F. Carré, 2009. Structural materials challenges for advanced reactor systems. J. Nuclear Mater., 385: 217-222. DOI: 10.1016/j.jnucmat.2008.11.026

Zhou, F., X.Z. Liao, Y.T. Zhu, S. Dallek and E.J. Lavernia, 2003. Microstructural evolution during recovery and recrystallization of a nanocrystalline $\mathrm{Al}-\mathrm{Mg}$ alloy prepared by cryogenic ball milling. Acta Mater., 51: 2777-27791. DOI: 10.1016/S1359-6454(03)00083-1

Zhou, J.B. and K.P. Rao, 2004. Structure and morphology evolution during mechanical alloying of Ti-Al-Si powder systems. J. Alloys Compounds, 384: 125-30. DOI: 10.1016/j.jallcom.2004.03.127 